\title{
MORFOLOGIA ORIGINAL E MORFOLOGIA ANTROPOGÊNICA NA DEFINIÇÃO DE UNIDADES ESPACIAIS DE PLANEJAMENTO URBANO: EXEMPLO NA METRÓPOLE PAULISTA
}

\author{
Cleide Rodrigues
}

\begin{abstract}
Resumo: Esse estudo representa parte do desenvolvimento e aplicação da metodologia para a abordagem do meio físico antrópico proposta por RODRIGUES (1990, 1997, 1999 e 2003). Nessa abordagem, coloca-se, entre outras necessidades, a do reconhecimento de sistemas geomorfológicos em seus diversos estágios de intervenção antrópica, tal como os estágios de pré-perturbação, de perturbação ativa e de pós-perturbação. Inclui-se também a perspectiva analítica na qual as intervenções humanas para a construção e manutenção desses ambientes são avaliadas enquanto ações geomorfológicas, portanto, passíveis de serem estudadas como intervenções em formas, materiais e processos. Nessa pesquisa, em particular, demonstra-se como formas originais semelhantes de alguns setores da metrópole paulista podem ser progressivamente derivadas em diversas formas antropogênicas. Parte-se do reconhecimento cartográfico das unidades morfológicas originais para posteriormente considerar a seqüência de intervenções antrópicas nas formas e na distribuição de materiais superficiais. Isso foi desenvolvido em testes para dois principais e complementares recortes escalares. Um deles foi realizado para a escala metropolitana, em 1:250000 para um período aproximado de cem anos e, o outro, para a escala de bacias hidrográficas de segunda e terceira ordens, predominantemente nas escalas 1:25000 e 1:10000 e períodos de trinta anos. Procura-se demonstrar como é possível identificar unidades espaciais semelhantes em suas combinações de morfologia original e antropogênica e como os processos atuais são dependentes do histórico da produção dessa nova morfologia urbana. Com isso, propõe-se a identificação dessas unidades para compor diversos instrumentos de planejamento urbano.
\end{abstract}

Palavras-chave: Geomorfologia Antropogênica; Impacto da urbanização; Geoindicadores da urbanização; Avaliação de impactos; Planejamento urbano.

\section{Introdução}

A partir de um conjunto de revisões da literatura em geomorfologia pura e aplicada, de experiências práticas de avaliação ambiental em diferentes regiões brasileiras e de testes realizados em diversas áreas do Brasil e Região Metropolitana de São Paulo (RMSP), foi sendo progressivamente definida e aperfeiçoada uma metodologia para o estudo do meio físico em seus diversos graus de intervenção antrópica. Nessa construção metodológica, testes no meio urbano vêm tendo maior destaque.

As orientações básicas dessa metodologia, expostas em RODRIGUES (1999 e 2003), reforçam a necessidade de superação de abordagens com ênfase nos elementos exclusivamente definidos pela natureza e apontam a importância de tratamento simultâneo e sistemático das interferências antrópicas.

Para denominar essa nova ênfase e essa maior complexidade na abordagem geomorfológica, vem sendo utilizada a denominação antropogeomorfologia, originalmente proposta por NIR (1982). Em concordância com esse e outros autores, orientações básicas foram sistematizadas e propostas, das quais destaca-se a adequação generalizada da utilização das ferramentas clássicas da geomorfologia, inclusive para a abordagem das ações antrópicas ao longo do tempo e do espaço e para o dimensionamento das mudanças no ambiente físico por elas geradas.

Dentre outras aplicações desses princípios e orientações básicas, destacados em RODRIGUES (2003), foram testados alguns dos procedimentos próprios da cartografia geomorfológica para diversas escalas e sistemas geomorfológicos da RMSP. Essa cartografia geomorfológica, denominada "geocartografia geomorfológica retrospectiva" ou "evolutiva", apóia-se no estudo sistemático do tripé morfológico: formas, materiais e processos da superficie terrestre (HART,1986). A diferença fundamental para outras abordagens é a consideração da própria interferência antrópica como ação geomorfológica, ação essa que pode: modificar propriedades e localização dos materiais superficiais; interferir em vetores, taxas e balanços dos processos e gerar, de forma direta e indireta, outra morfologia, aqui denominada de morfologia antropogênica.

Dessa cartografia geomorfológica evolutiva, que inclui, dentre outros aspectos, a morfologia original e a morfologia antropogênica, foi sendo evidenciada a importância desses últimos conteúdos para a compreensão de vários processos hidrogeomorfológicos atuais em áreas urbanas. Puderam ser melhor dimensionados e compreendidos determinados processos e até 
mesmo melhor discriminados agentes sociais responsáveis pela produção dessa vasta superfície urbana, de alta derivação antrópica no meio tropical úmido. Esses estudos têm também contribuído com a discussão e aperfeiçoamento da lista dos geoindicadores de mudanças ambientais, iniciativa internacional vinculada à IUGS (International Union of Geological Science) conforme RODRIGUES e COLTRINARI (2004).

A proposta aqui apresentada constitui parte dos resultados de estudos cartográficos da região metropolitana que foram realizados em duas escalas complementares, ambas tratando de identificar e representar a morfologia original (morfologia representativa de fases pré-intervenção morfológica, nesse caso, pré-urbana) e a seqüência de intervenções nas formas e materiais superficiais (morfologias representativas de fases de perturbação ativa e de fases pós-perturbação). Da correlação entre esses conteúdos cartográficos, foram identificadas outras unidades espaciais, de caráter mais complexo, que reúnem simultâneamente, características semelhantes quanto a esses dois conjuntos de dados. Foram identificadas unidades morfológicas complexas que se revelaram semelhantes quanto à sua dinâmica hidrogeomorfológica nos testes realizados até o momento. Assim, chegase a propor a utilização dessa metodologia e de suas categorias e conteúdos como forma auxiliar no planejamento urbano, seja para instruções de caráter preventivo ou de recuperação.

\section{Métodos e Técnicas}

A revisão da literatura nas áreas de geomorfologia pura e aplicada constituiu procedimento básico para que os testes fossem progressivamente realizados e a metodologia construída. Essa construção foi fundamentada numa concepção de geomorfologia que permite abordar as recentes e profundas mudanças impostas pelas sociedades humanas na superfície terrestre. Essa concepção de objeto, significativamente presente na literatura geomorfológica contemporânea inglesa, define o estudo geomorfológico como o estudo das formas, dos materiais superficiais (rochas, solos e demais materiais) e dos processos da superfície terrestre, tomados em suas diversas expressões espaço-temporais (HART,1986). Experiências com avaliações de impacto no meio físico realizadas desde 1984 em vastas áreas do território brasileiro e com intervenções de grande porte (linhas de transmissão, usinas hidrelétricas, ferrovias e dutos) também formam 0 substrato dessa proposição e de sua aplicação.

Da literatura em geomorfologia aplicada, são relevantes algumas obras, das quais orientações básicas foram obtidas. São elas: "Geomorphology, Pure and Applied" de HART (1986),
"Anthropogeomorphology" de NIR (1983), "Applied Geomorphology: Geomorphological Survey for Environmental Development" de VERSTAPPEN (1983), "Géomorphologie Aplicable" de TRICART (1978), "Geomorphology and Reclamation of Disturbed Lands" de TOY e HADLEY (1987). O uso dos termos antropogeomorfologia, fases de perturbação antrópica, tipos de perturbação ou intervenção, morfologia antropogênica, materiais tecnogênicos, advém dessa revisão. Alguns procedimentos, como o de reconhecer inicialmente a morfologia original representativa de fase pré-perturbação ou a morfologia das fases de perturbação ativa, foram também selecionados dessa revisão.

A revisão alcançou também a literatura de avaliação de impactos no meio físico em experiências em todo o mundo, mesmo diante da dificuldade de acesso, do grande volume, da ausência de sistematização, pois se trata, na maior parte dos casos, de material bibliográfico ou relatórios técnicos de fora do meio acadêmico.

Da revisão de estudos geomorfológicos e geológicos aplicados em áreas urbanas, merece destaque os que produziram instrumentos de planejamento com conteúdos geomorfológicos, tais como: carta geotécnica, carta de aptidão ao assentamento urbano e zoneamento urbano. Também foram revisados estudos voltados ao reconhecimento de mudanças de taxas de processos em ambientes urbanizados. Dessa revisão específica também se pode construir a metodologia em seu conjunto.

RODRIGUES $(1999,2003)$ apresentou orientações básicas para se estudar os efeitos das ações antrópicas no meio físico:

a) observar as ações humanas como ações geomorfológicas na superfície terrestre;

b) investigar nas ações humanas padrões significativos para a morfodinâmica;

c) investigar a dinâmica e a história cumulativa das intervenções humanas, iniciando com os estágios pré-perturbação;

d) empregar diversas e complementares escalas espaçotemporais;

e) empregar e investigar as possibilidades da cartografia geomorfológica de detalhe;

f) explorar a abordagem sistêmica;

g) usar a noção de limiar geomorfológico e a análise de magnitude e freqüência;

h) dar ênfase à análise integrada em sistemas geomorfológicos;

i) levar em consideração as particularidades dos contextos morfoclimáticos e morfoestruturais;

j) ampliar o monitoramento de balanços, taxas e geografia 
dos processos derivados e não derivados de ações antrópicas.

Os procedimentos específicos, ora apresentados, são apenas parte dessa busca mais ampla que inclui o conjunto de atividades práticas em processos de planejamento. Representa, contudo, alguns dos testes mais significativos que podem ser considerados simultaneamente procedimento e resultado. A condução baseou-se, de forma geral, nesses princípios e orientações adotando-se efetivamente: (a) a utilização da cartografia geomorfológica (ainda que em alguns casos, parcialmente realizada); (b) a utilização de escalas diversas e complementares para a análise; (c) a utilização e produção de conhecimento geomorfológico das condições originais da superfície estudada, ou seja, da morfologia original ou representativa de estágios pré-intervenção; (d) a identificação e utilização de padrões de intervenção humana significativos para a morfodinâmica; (e) a análise das interferências humanas como interferências de natureza geomorfológica; (f) a produção de conhecimento e análise das seqüências e sobreposições de intervenção urbana; $(\mathrm{g})$ o reconhecimento dos conteúdos em diversas e complementares escalas; (h) a utilização de sistemas geomorfológicos com o reconhecimento cartográfico de seus limites em cada escala estudada como referências-chave da correlação subseqüente.

\section{Morfologia Original}

A etapa inicial da pesquisa deu-se com o reconhecimento da morfologia original nas escalas 1:250000, 1:25000 e 1:10000, por meio de técnicas tradicionais da cartografia geomorfológica, ou seja, sensoriamento remoto (principalmente fotografias aéreas) conjugado com reconhecimento e levantamento de campo.

Entende-se por morfologia original, ou pré-intervenção, aquela morfologia cujos atributos como extensão, declividades, rupturas e mudanças de declives, dentre outros, não sofreram alterações significativas por intervenção antrópica direta ou indireta. Modificação significativa é aquela que já implica em dimensões métricas nos atributos mencionados.

Em LIMA (1990) existe uma classificação de categorias de intervenção que parte de um primeiro grupo de intervenções morfológicas, denominadas intervenções de primeira ordem, nas quais a urbanização é uma das principais. Outra importante categoria, também de primeira ordem é a intervenção para retirada da vegetação original.

Subdividindo-se as categorias de primeira ordem, outros tipos de interferência podem ser detalhados. Por exemplo, a categoria de intervenção urbanização poderá ser detalhada por padrão de arruamento, por densidade de edificações, densidade de lotes ou por fases de consolidação urbana. Pode ser ainda mais detalhada de acordo com a extensão, profundidade, densidade dessas novas formas ou pelo volume de remanejamento ou substituição de materiais superficiais originais (RODRIGUES e COLTRINARI, 2004). Para outras categorias de primeira ordem, como mineração, intervenções lineares de sistema viário ou intervenções por uso agrícola, NIR (1983) advoga que outros detalhamentos também devem ser realizados.
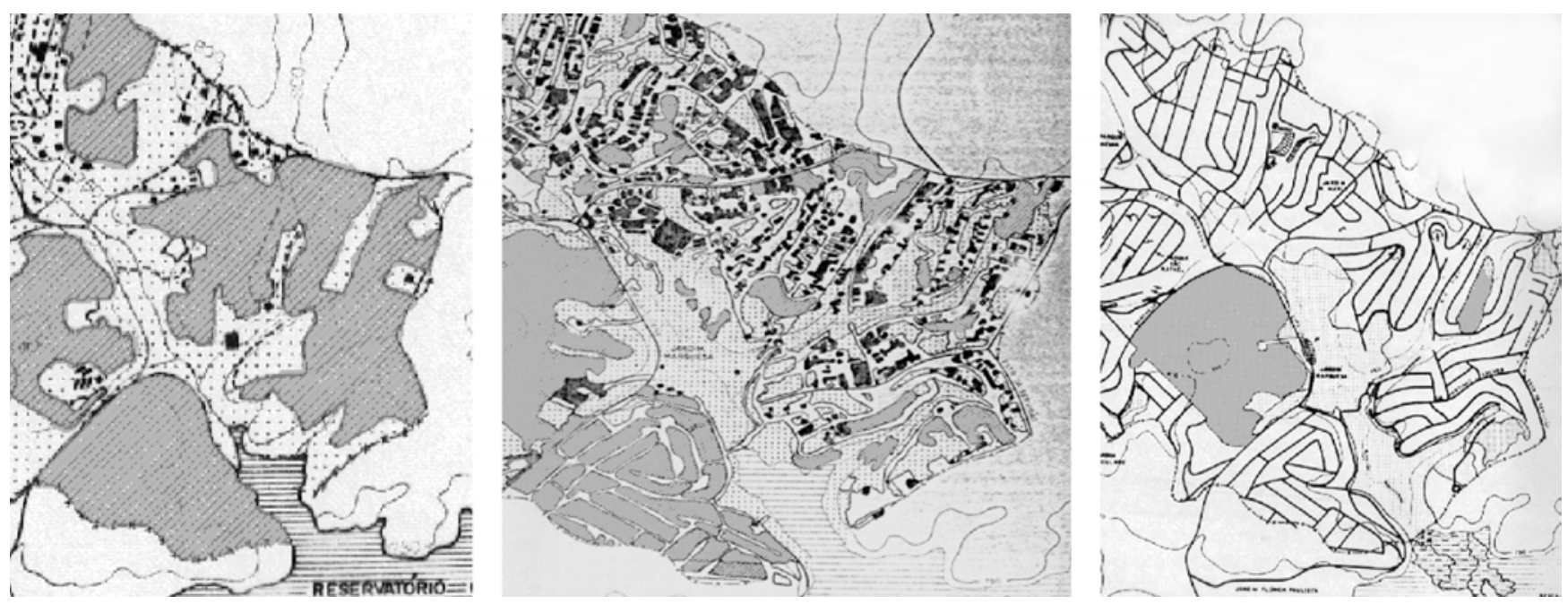

Morfologia original discriminada na escala 1:25000

Morfologia antropogênica discriminada na escala 1:25000

Figura 1 Cartografia geomorfológica retrospectiva do Ribeirão Guavirutuba, RMSP. Fonte: LIMA (1990). 


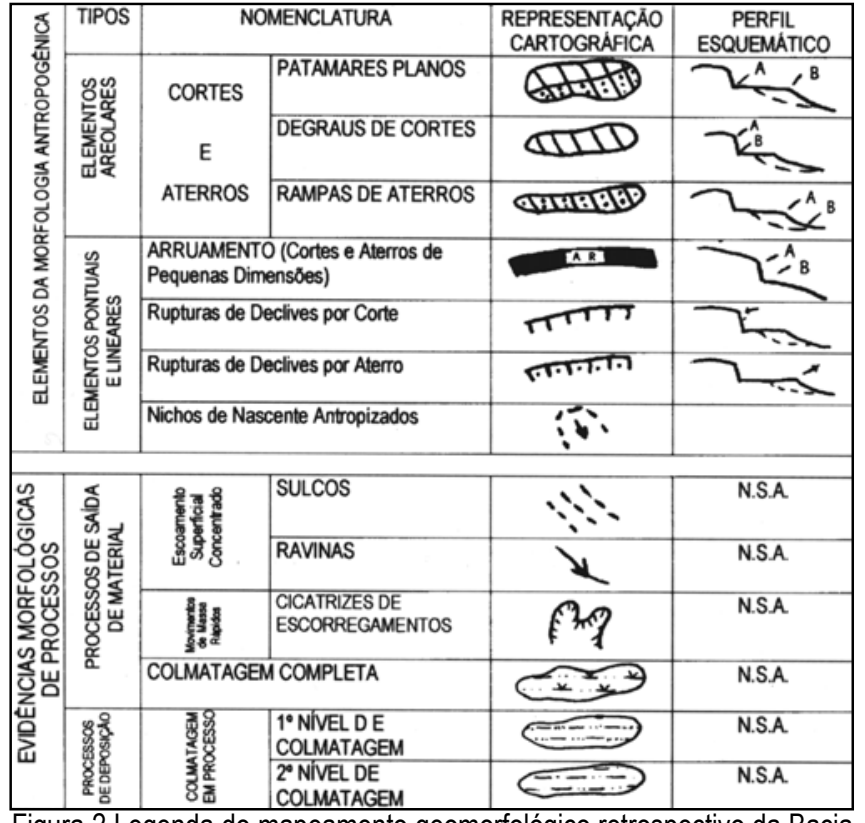

Figura 2 Legenda do mapeamento geomorfológico retrospectivo da Bacia do Rio Guavirituba. Fonte: RODRIGUES, 2004.

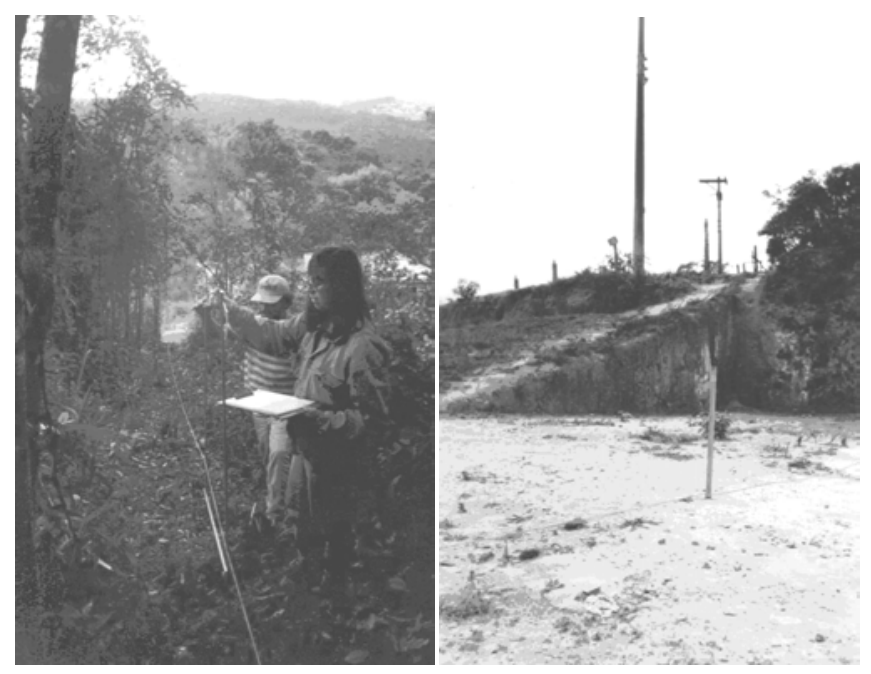

Foto 1 Levantamento de perfis em áreas de morfologia original preservada. Abertura de picada e uso de pantógrafo, cordas e bússola. Foto: Cleide Rodrigues. Foto 2 Cortes aproveitados para a caracterização morfométrica, pedológica, litológica, morfológica e dos materiais antropogênicos. Foto: Waldirene do Carmo.

Assim, a morfologia original é a que não sofreu intervenção direta nas formas originais, ou seja, os sistemas geomorfológicos podem ter sido objeto de interferências importantes do ponto de vista dos processos, como no caso da ação do desmatamento, mas não sofreram remanejamentos diretos significativos de material como aqueles que ocorrem em áreas com aragem, pastagem intensiva e uso de trator (superfícies agrícolas) ou cortes, aterros e substituição por materiais tecnogênicos (superfícies urbanas).

0 reconhecimento da morfologia original das escalas maiores baseou-se no uso de cartas topográficas nas escalas 1:25000 e 1:10000 (Fig. 1) e de fotografias aéreas em 1:18000 e 1:10000 (Fig. 2). Foi selecionada documentação mais antiga, ou seja, aquela com maiores condições de apresentar janelas ou chaves para a caracterização e reconhecimento da distribuição espacial dessa morfologia. Dentre outros conteúdos, foram levantados: a geometria de vertentes (retilinidades, convexidades, concavidades), a posição (terço superior, médio ou inferior), subunidades de vertentes (anfiteatros de nichos de nascentes, rupturas, mudanças, etc.) conforme exemplo das Figs. 1 e 2 .

Em campo, além de verificar a fotointerpretação, foram levantados perfis e caracterizadas as vertentes em seus atributos pedológicos e litológicos (Fotos 1 e 2). Esses estudos de maior detalhe deram-se preferencialmente em áreas com predomínio de embasamento cristalino pré-Cambriano, com diversas litologias tais como: micaxistos, migmatitos, gnaisses e, secundariamente, granitóides. Foi dada preferência também às áreas onde há uma interface mais complexa entre pacotes sedimentares Terciários da Formação São Paulo e o embasamento cristalino, ou seja, onde esses dois grandes conjuntos afloram no mesmo sistema geomorfológico, fosse um sistema interfluvial ou uma vertente.

Foram considerados os seguintes atributos das formas: declividade, extensão de vertentes, geometria de sub-setores de vertentes, rupturas e mudanças originais além de parâmetros morfológicos dos materiais superficiais e solos, como profundidade, textura, estrutura e transição entre horizontes pedológicos. A identificação das litologias e de parte de suas descontinuidades internas também foram levantadas. Essas informações serviram para definir unidades morfológicas semelhantes, face à abrangência do conceito de morfologia adotado. Por exemplo, concavidades superiores de vertentes, mesmo apresentando geometria e declividades semelhantes (aspectos morfológicos e morfométricos da vertente) foram diferenciadas quanto ao substrato, solos e formações superficiais (aspectos morfológicos do conteúdo material dessas formas).

A morfologia original foi caracterizada no Jardim Sofia e Jardim Popular (Diadema - RMSP), na região da represa de Guarapiranga (quatro diferentes áreas na bacia hidrográfica do Ribeirão Guavirutuba, na região de M'Boi Mirim e no Bairro do Jusa), no Município de Ribeirão Pires (bacia hidrográfica de segunda ordem) e no Município de São Paulo (região do Morumbi e Favela Nova República). 


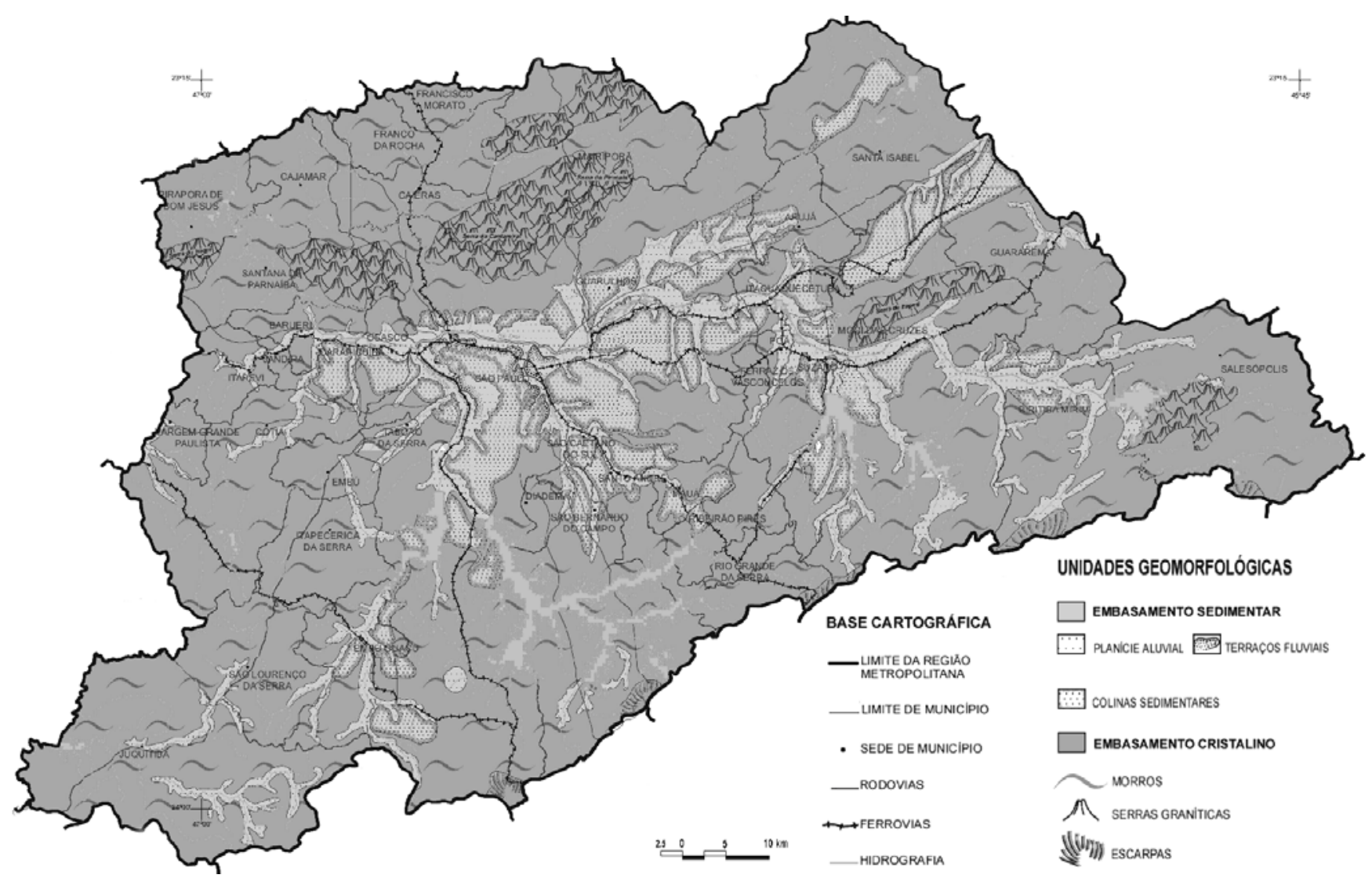

Figura 3 Morfologia original da RMSP (esc. orig. 1:500000). Fonte: RODRIGUES (2004) e BATISTA (2003).

0 reconhecimento da morfologia original na escala metropolitana (Fig. 3) foi sistematizado em etapa posterior, quando já existia um significativo acúmulo de informações em escalas mais detalhadas (BATISTA e RODRIGUES, 2003). Isso foi necessário em função dos procedimentos ditados pela cartografia geomorfológica, ao tratar de generalizações, e também pelo fato de serem usadas informações secundárias de três diferentes autores: ALMEIDA (1957), AB'SABER (1957) e Estado de São Paulo/ SNM/EMPLASA (1992). Foi necessário cotejar diferentes áreas mapeadas com diferentes representações cartográficas e conteúdos geomorfológicos à luz do conhecimento geológico atual, pois, do ponto de vista geomorfológico, o conhecimento cartográfico atual é disperso. Contudo, esse conhecimento geomorfológico disperso e mais detalhado também balizou a sistematização. Os trabalhos de campo acumulados foram indispensáveis.

\section{Morfologia Antropogênica}

Em etapas posteriores foi cartografada a morfologia antropogênica em seqüências cronológicas. Para essa identificação, utilizou-se a hierarquia de intervenções sugerida por LIMA (1990) aperfeiçoada.

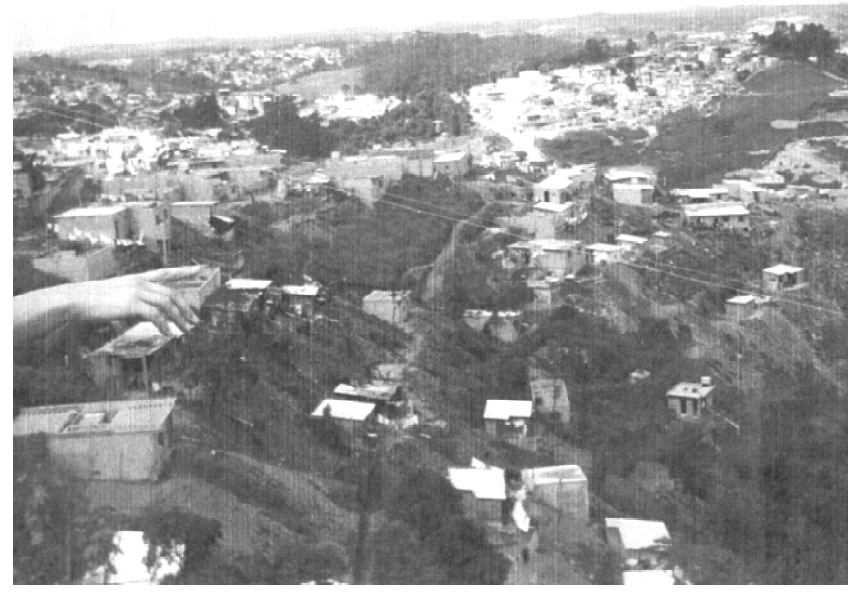

Foto 3 Exemplo de morfologia antropogênica em Guarapiranga, estágio de perturbação ativa, padrão classe pobre, morfologia original de morrotes de alta dissecação em micaxistos e migmatitos. Foto: Waldirene do Carmo, 1994. 
O mapeamento da morfologia antropogênica em escalas de detalhe baseou-se no padrão de arruamento, densidade de edificações, estágio de consolidação urbana, distribuição e densidade de materiais superficiais, profundidade e extensão de cortes e aterros, volume de materiais remanejados in loco ou importados. Esses dados foram obtidos de diversas formas, pela foto- interpretação de seqüências cronológicas de intervenção, pela análise de cartografia de base de diversas épocas, por entrevistas e levantamentos de campo. Parte da morfologia antropogênica foi levantada com os recursos tradicionais de levantamento de perfis de vertentes adequado à morfologia original (Fotos $1 \mathrm{e} 2$ ).

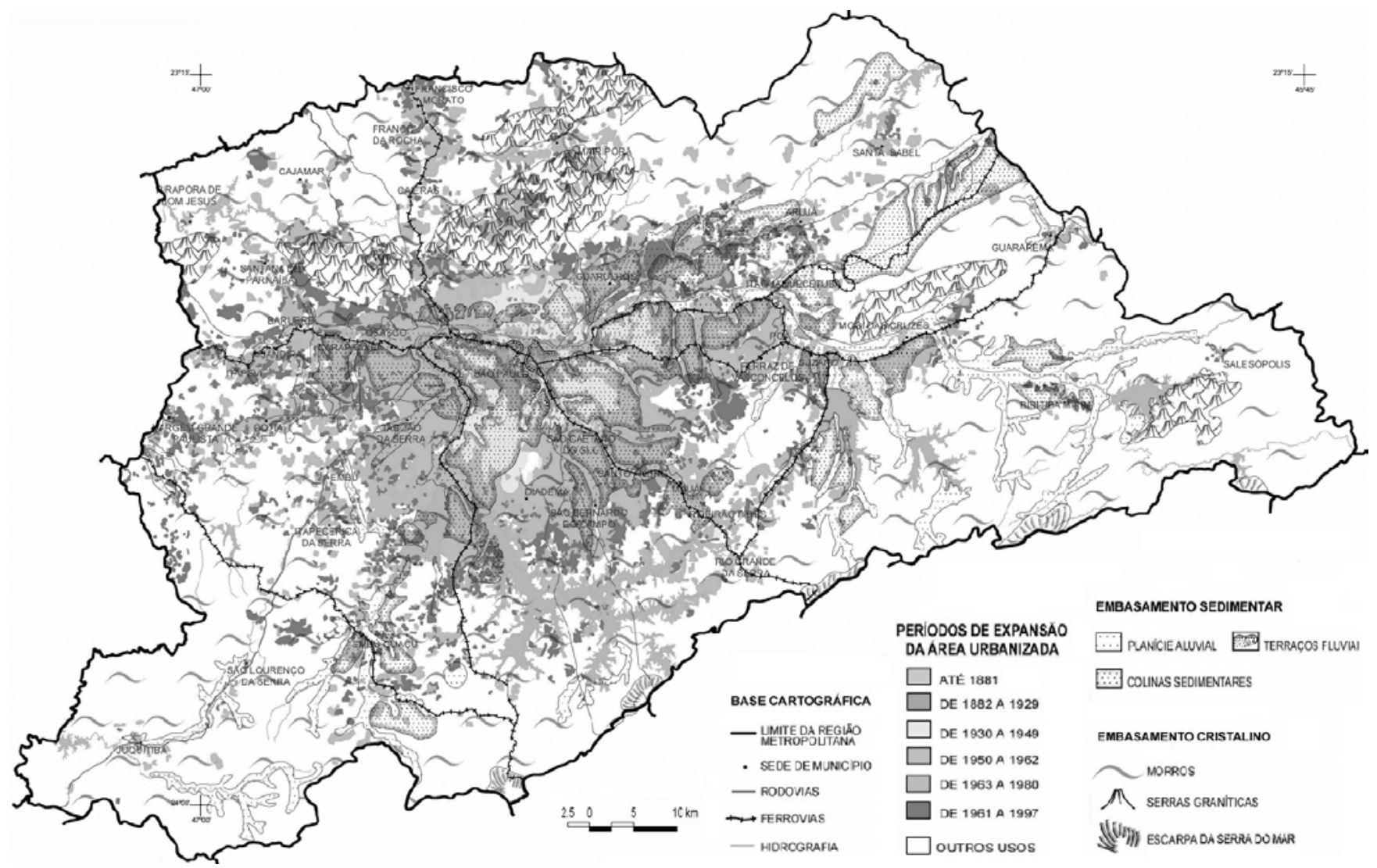

Figura 4 Morfologia antropogênica - RMSP (esc. orig. 1:500000). Fonte: RODRIGUES (2004) e BATISTA (2003).

Tabela 1 Morfologia original e seqüência de intervenções urbanas na metrópole paulista.

\begin{tabular}{|c|c|c|c|c|c|c|c|c|c|c|c|c|}
\hline \multirow{3}{*}{$\begin{array}{l}\text { PERIODOS DE } \\
\text { EXPANSÃO URBANA }\end{array}$} & \multicolumn{4}{|c|}{ EMBASAMENTO SEDIMENTAR } & \multicolumn{6}{|c|}{ EMBASAMENTO CRISTALINO } & \multirow{2}{*}{\multicolumn{2}{|c|}{ TOTAL }} \\
\hline & \multicolumn{2}{|c|}{$\begin{array}{l}\text { PLANÍCIE DE } \\
\text { INUNDAÇÃOO }\end{array}$} & \multicolumn{2}{|c|}{$\begin{array}{l}\text { TERRAÇOS FLU- } \\
\text { VIAIS E COLINAS } \\
\text { SEDIMENTARES }\end{array}$} & \multicolumn{2}{|c|}{ MORROS } & \multicolumn{2}{|c|}{ SERRAS } & \multicolumn{2}{|c|}{ ESCARPAS } & & \\
\hline & $\mathrm{km}^{2}$ & $\%$ & $\mathrm{~km}^{2}$ & $\%$ & $\mathrm{~km}^{2}$ & $\%$ & $\mathrm{~km}^{2}$ & $\%$ & $\mathrm{~km}^{2}$ & $\%$ & $\mathrm{~km}^{2}$ & $\%$ \\
\hline ATÉ 1929 & 20,61 & 2,36 & 71,91 & 7,36 & 1,63 & 0,03 & 0,00 & 0,00 & 0,00 & 0,00 & 94,15 & 1,26 \\
\hline DE 1929 - 1962 & 211,23 & 24,23 & 417,90 & 42,76 & 328,30 & 5,91 & 6,77 & 1,39 & 0,41 & 0,77 & 964,62 & 12,94 \\
\hline DE $1963-1997$ & 121,71 & 13,96 & 155,87 & 15,95 & 872,39 & 15,72 & 90,13 & 18,49 & 0,00 & 0,01 & 1084,24 & 14,55 \\
\hline OUTRAS INTERVENÇÕES & 518,14 & 59,44 & 331,66 & 33,93 & 4348,54 & 78,34 & 390,65 & 80,13 & 53,14 & 99,22 & 5310,47 & 71,25 \\
\hline TOTAL & 871,70 & 100,00 & 977,34 & 100,00 & 5580,85 & 100,00 & 487,55 & 100,00 & 53,56 & 100,00 & 7453,47 & 100,00 \\
\hline
\end{tabular}

Fonte: RODRIGUES (2004). 
A identificação da morfologia antropogênica nas escalas de menor detalhe (Fig. 4) foi realizada de acordo com as orientações anteriormente descritas, ou seja, teve que ser levantada em diversas e subseqüentes fases de intervenção urbana. Para isso foram utilizados documentos antigos e recentes, como cartas topográficas, mosaicos e fotografias aéreas antigas e as cartas de evolução do uso da terra (Estado de São Paulo/SNM/EMPLASA, 1992 apud BATISTA, 2003).

BATISTA (2003) pesquisou as categorias e os procedimentos utilizados em cartografia do uso da terra para verificar a possibilidade de uso, simplificação e correlação com as unidades da morfologia original da carta organizada por RODRIGUES e BATISTA (2004). Mesmo sem poder contar com a discriminação de categorias de urbanização sugeridas na metodologia e discerníveis na escala adotada (como, por exemplo, área de verticalização densa, área de loteamento de classe pobre, área de parque, loteamento inicial com arruamento), foi usada a simplificação de BATISTA (2003) verificada por outros documentos.

Dessa forma, a categoria "intervenção urbana" não pôde ser cartografada em detalhe devido às restritas possibilidades de generalização dos mapeamentos disponiveis. Todas as informações de intervenção urbana foram reunidas numa mesma categoria; área urbanizada. 0 mérito da escolha reside na possibilidade de correlação cartográfica com a morfologia original.

Outro procedimento importante que merece ser descrito é 0 da correlação cartográfica desses documentos em escalas 1 : 250000 que trazem informações da morfologia antropogênica e da morfologia original. Essa correlação permitiu identificar as unidades geomorfológicas mais preservadas ou mais transgredidas ao longo do tempo pela expansão urbana (Tab. 1). Esse procedimento auxiliou a obtenção de visão de conjunto para a posterior identificação de unidades morfológicas complexas, ou seja, as que agregam características de sua situação pré-intervenção e de seqüências de intervenção urbana semelhantes e irão constituir as unidades de planejamento urbano.

\section{Resultados}

Os resultados do estudo podem ser considerados substantivos e metodológicos pois se referem tanto ao conhecimento territorial em si, como também a avanços no método, incluindo a possibilidade de sua aplicação. Destacam-se a seguir resultados.

\section{$\mathrm{Na}$ escala metropolitana}

(a) Da sistematização cartográfica em 1:250000 da morfologia original da RMSP foi possivel discriminar as seguintes unidades da morfologia original: planície de inundação, terraços fluviais, colinas em embasamento sedimentar, morros, serras e escarpas.

(b) Sistematização cartográfica da morfologia antropogênica na escala 1:250000, representativa da categoria de intervenção urbanização numa seqüência temporal de cerca de cem anos. Apesar de ter sido realizada com simplificações e dados secundários verificados em aerofotos e imagens de satélite, além de usar apenas a categoria urbanização de forma indiscriminada, essa sistematização demonstrou grande potencial de leituras e interpretações, ainda não plenamente exploradas.

(c) Correlação cartográfica em 1:250000 da morfologia original e da morfologia antropogênica e a posterior identificação de unidades complexas. As simplificações utilizadas nos conteúdos mostraram-se importantes para a obtenção de uma leitura cartográfica sem ruídos significativos. Verificou-se, contudo, que a correlação cartográfica comportaria a inclusão de algumas categorias de intervenção urbana ainda nessa escala cartográfica, tais como: verticalização com alta densidade, loteamentos em implantação, aterros de grande porte, dentre outras. A correlação cartográfica revelou grande potencial de leituras geomorfológicas também ainda pouco exploradas. Por exemplo, foi possível identificar a apropriação seletiva de compartimentos geomorfológicos até as décadas iniciais do século XX e o posterior maior nivel de transgressão em unidades menos propícias à urbanização, tais como: as planícies de inundação e os morros do embasamento cristalino que passam a ser ocupados intensamente a partir das décadas de sessenta. Esse documento foi fundamental para a proposição de algumas das unidades complexas, descritas adiante, a título de exemplo.

\section{Nas escalas de detalhe}

(a) Levantamentos cartográficos e de perfis topográficos da morfologia original dos arredores do reservatório de Guarapiranga em 1:10000 e em 1:25000, de bacia hidrográfica de primeira ordem pertencente ao córrego Pirajussara (Favela Nova República), de interflúvio e bacia de primeira ordem no Município de Ribeirão Pires, da bacia hidrográfica de terceira ordem nos bairros de Jardim Sofia e Jardim Popular no Município de Diadema e da região de M'Boi Mirim. Esses levantamentos permitiram identificar correlações relevantes entre determinados valores de atributos morfológicos (declividades, extensão de vertentes, dimensão de anfiteatros de cabeceiras de drenagem, etc.) com os tipos litológicos. Permitiram também reconhecer diferenças morfológicas importantes e recorrentes entre as margens direita e esquerda de bacias hidrográficas nas regiões da borda da bacia sedimentar de São Paulo e em áreas com predomínio de micaxistos e migma- 
titos. O reconhecimento dessa morfologia original da superfície, bem como a morfologia dos materiais superficiais e rochas, possibilitou também verificar a importância dos sedimentos Terciários e de suas descontinuidades intra-formacionais no desenvolvimento dos maiores e mais íngremes anfiteatros côncavos de cabeceiras de drenagem. Esses reconhecimentos e correlações apresentam grande valor para o planejamento. Por exemplo, são encontradas associações de fatos da morfologia original e da morfologia antropogênica onde há maior freqüência de determinados episódios de movimentos de massa em áreas urbanas. Há forte correlação entre os anfiteatros de nichos de nascentes, os mais amplos e íngremes sub-elementos das vertentes originais, com aterros não compactados e heterogêneos (morfologia antropogênica) na maior parte desses escorregamentos.

(b) Levantamentos da morfologia antropogênica, que foram inicialmente sistematizados por cartografia geomorfológica evolutiva em escalas de detalhe e posteriormente verificados em trabalhos de campo. Nesses, discriminaram-se padrões de urbanização de acordo com a densidade das formas antrópicas, como, por exemplo, cortes e aterros, edificações e suas dimensões, profundidade de remanejamento de materiais superficiais, volume de materiais remobilizados in situ, volume de materiais tecnogênicos importados de outras áreas ou sistemas geomorfológicos, estágio de consolidação urbana, dentre outros parâmetros descritores. Esses documentos cartográficos e levantamentos de campo auxiliaram a identificação de padrões de intervenção como a definição das unidades morfológicas complexas

\section{Nas duas escalas}

Com todos esses levantamentos e experiências, foi possível iniciar um trabalho de identificação das unidades morfológicas complexas de maior relevância na metrópole. Dessas unidades, destacaram-se como importantes para 0 planejamento, unidades espaciais complexas situadas em concavidades superiores nos espigões, em concavidades superiores na borda da bacia sedimentar de São Paulo, em morros, uma unidade no espigão, diversas unidades em antigas planícies de inundação, unidades em divisores interfluviais nos morros, dentre outras. A cartografia completa dessas unidades não foi realizada, contudo, a metodologia para sua identificação foi plenamente proposta e testada. Seguem exemplos de unidades morfológicas complexas identificadas (também denominadas de unidades espaciais de planejamento) resultantes dessa combinação de conteúdos.

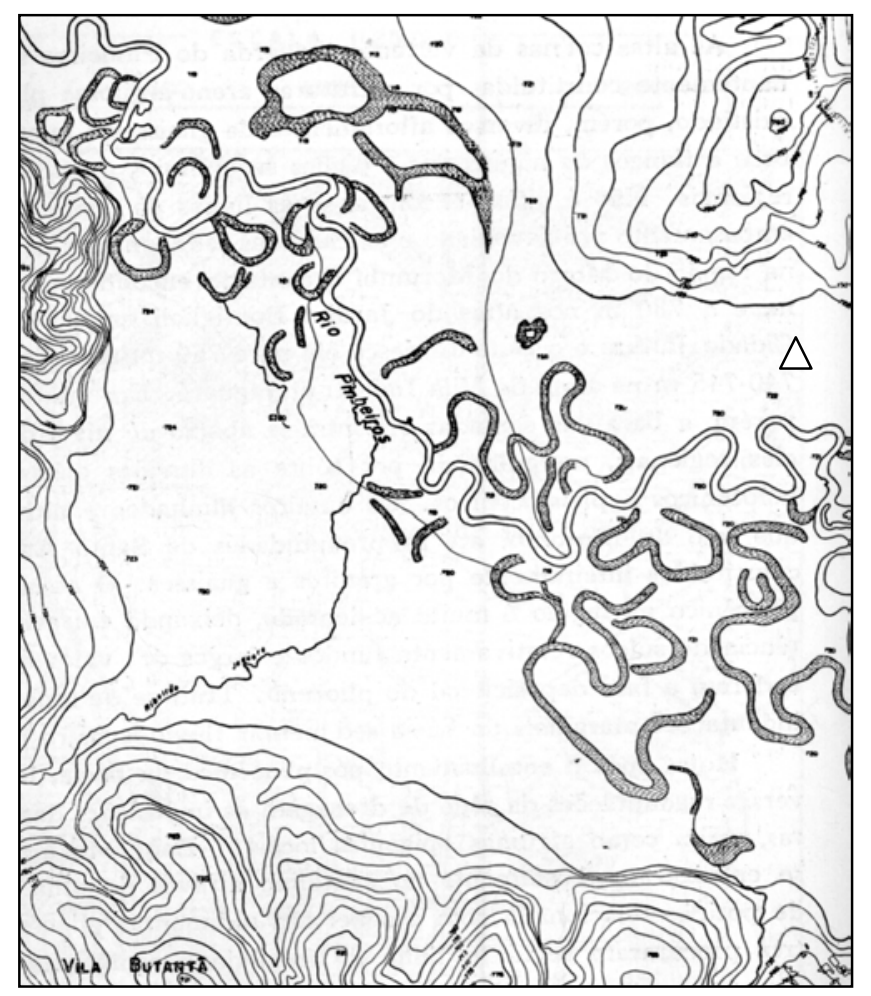

Figura 4 Cinturão meândrico do Rio Pinheiros e áreas de backswamps. Fonte: AB'SABER, 1957.

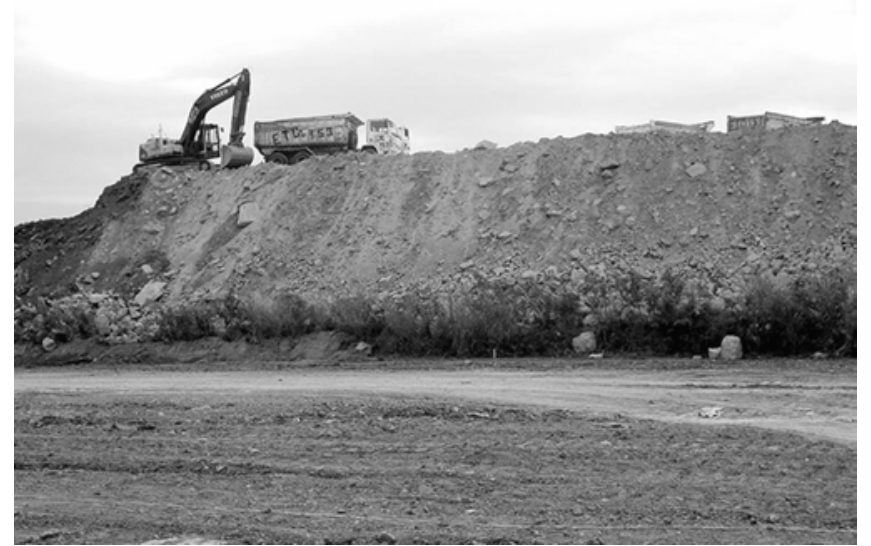

Foto 5 Exemplo de morfologia antropogênica e material tecnogênico na antiga backswamp no atual Parque Villa lobos. Local assinalado com triângulo na Fig. 4. Foto: Eduardo Justiniano.

(a) Na planície de inundação foram mapeadas unidades que originalmente eram backswamps, áreas mais rebaixadas da planície de inundação original e que foram drenadas por retificação fluvial, retirada ou substituída sua vegetação original e aterrada com material tecnogênico diversificado (botas-foras, desassoreamento, entulho, lixões, etc.), por exemplo, o Parque 
Vila Lobos e arredores (Fig. 4 e Foto 3). A morfodinâmica atual dessa unidade complexa apresenta problemas semelhantes: problemas de drenagem interna, necessidade de compactação e de instalação de sistema de drenagem para os equipamentos urbanos, necessidade de tratamento topográfico e de importação de terra vegetal para intervenções paisagísticas. Nos arredores, onde não se observa a sedimentação e construção desse terraço tecnogênico, existe a tendência de maior ocorrência de inundações e outras dificuldades de drenagem e de saneamento.

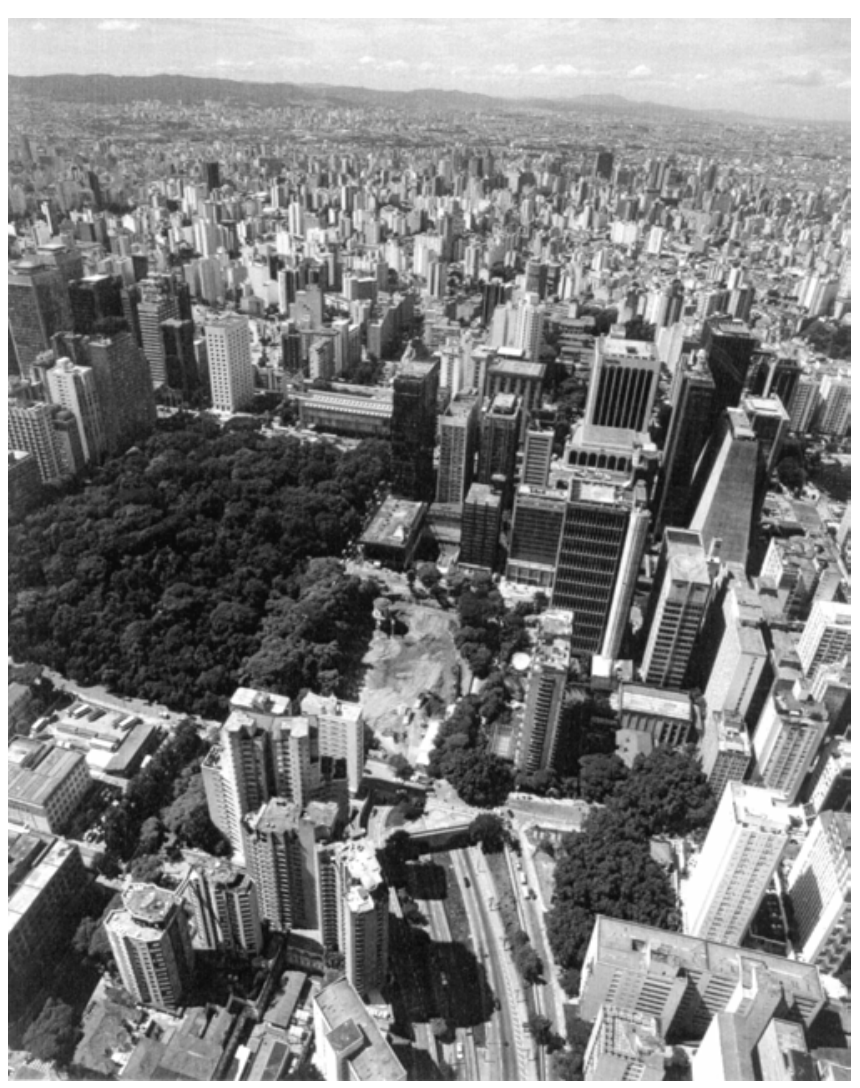

Foto 6 Exemplo de morfologia antropogênica no espigão da Avenida Paulista. Foto: Lilian Rosa de Jesus.

(b) Nos espigões foram mapeadas unidades morfológicas originais de interflúvios assentados sobre sedimentos Terciários da Formação São Paulo, inicialmente sistemas geomorfológicos dispersores e que sofreram desmatamento, remanejamento de materiais superficiais por arruamentos e loteamentos iniciais, substituição de vegetação original por espécies exógenas, edificação inicial de média densidade com materiais tecnogênicos, e de baixa profundidade de intervenções subterrâneas, deposição de material tecnogênico de sub-leito e leito de pavimentação, posterior interferência de grandes edificações e de fundações profundas, sistemas subterrâneos (abastecimento, saneamento e comunicação), sistema viário superficial e subterrâneo com metrô e túneis. Essa unidade também apresenta hoje problemas ligados ao rompimento de dutos subterrâneos e de drenagem subterrânea concentrada, cujo porte pode colocar em risco a estabilidade da superficie em locais circunscritos, principalmente os locais mais próximos à antiga morfologia de concentração de fluxos que antecedem as antigas cabeceiras de drenagem das duas vertentes dos rios Pinheiros e Tietê adjacentes (Foto 6).

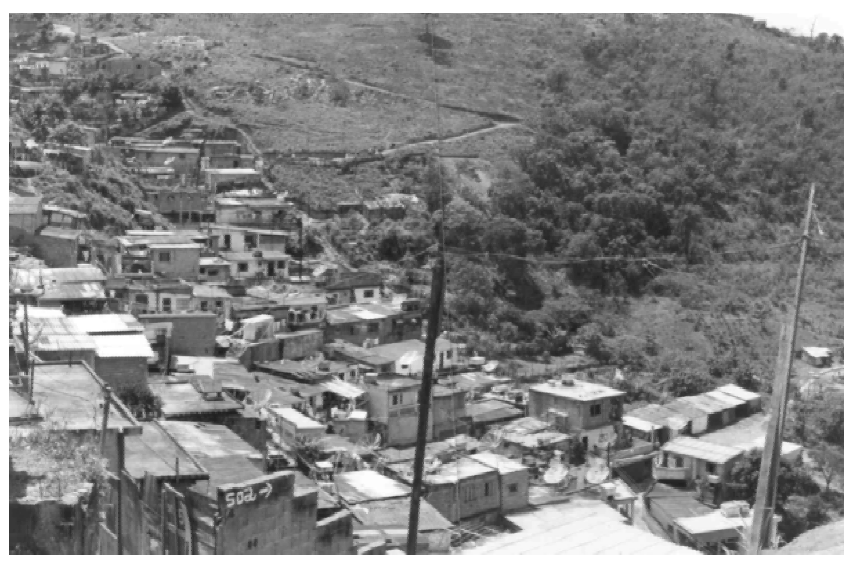

Foto 7 Exemplo de padrão urbano classe pobre, morfologia original de morrotes em embasamento cristalino, estágios pré e pós-intervenção. Foto: Cleide Rodrigues.

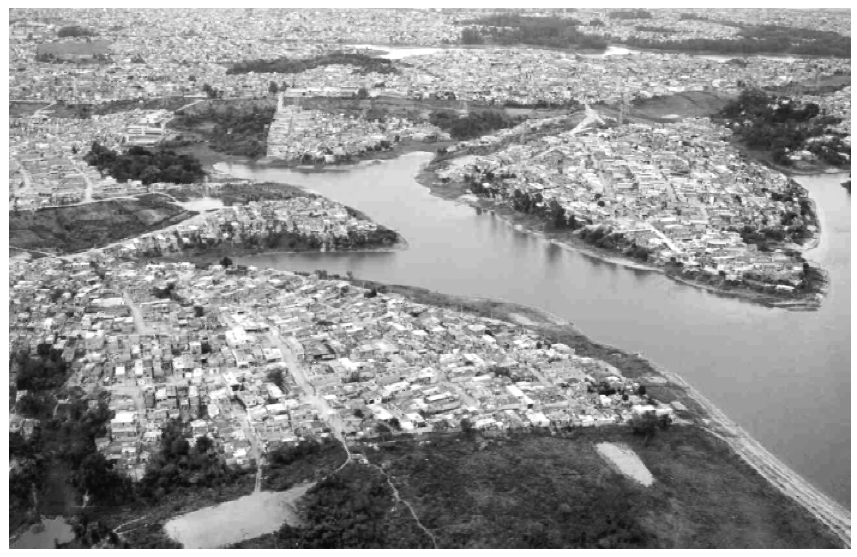

Foto 8 Exemplo de padrão urbano classe pobre, morfologia original de morrotes em embasamento cristalino e colinas em embasamento sedimentar Terciário, estágio pós-intervenção. Foto: Angela Garcia.

Um exemplo de anfiteatro amplo na interface sedimentos terciários (embasamento gnáissico), com deposição de materiais tecnogênicos diversificados e não compactados foi apresentado em RODRIGUES (2004). 0 mesmo exercício de correlação de conteúdos e de leituras sobre o comportamento morfo-hidrodinâmico foi realizado nessa unidade e nas demais unidades complexas identificadas. 


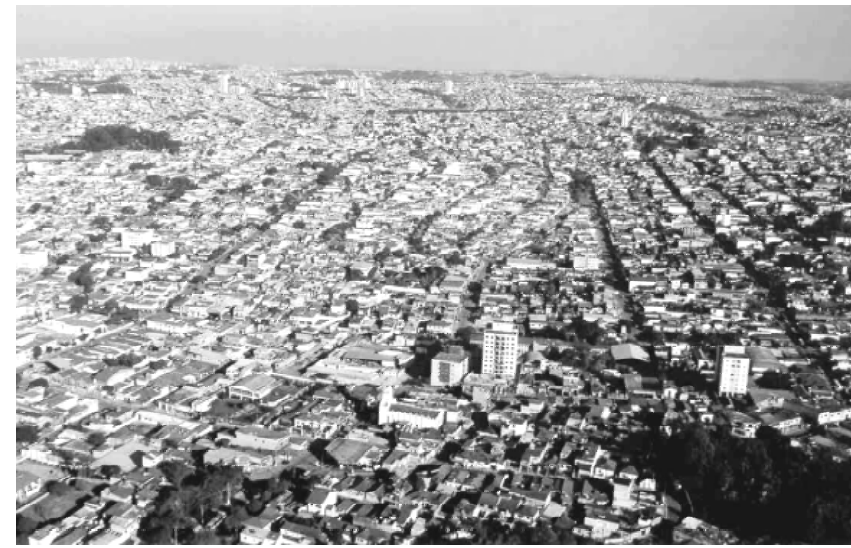

Foto 9 Exemplo de padrão urbano classe média, morfologia original de espigão em terrenos sedimentares Terciários, estágio pós-intervenção. Foto: Angela Garcia.

\section{Considerações finais}

Este estudo propõe a consideração simultânea da morfologia original (com todos os conteúdos morfológicos discriminados) e da seqüência de intervenções morfológicas urbanas para a identificação de unidades com hidrodinâmica atual semelhante. Uma vez identificadas essas unidades com comportamento físico uniforme (as denominadas unidades espaciais complexas), estarão identificadas formas de intervenção e de mitigação de impactos mais adequadas a cada uma delas. 0 fato de ser possível espacializar ou cartografar, coloca a metodologia num plano ainda mais adequado à produção de instrumentos de planejamento físico-territorial urbano.

Considera-se que a proposição de categorias de análise, de conceitos-chave, de terminologia, de procedimentos e instrumental de pesquisa sejam os principais resultados de ordem metodológica dos estudos sumariamente relatados.

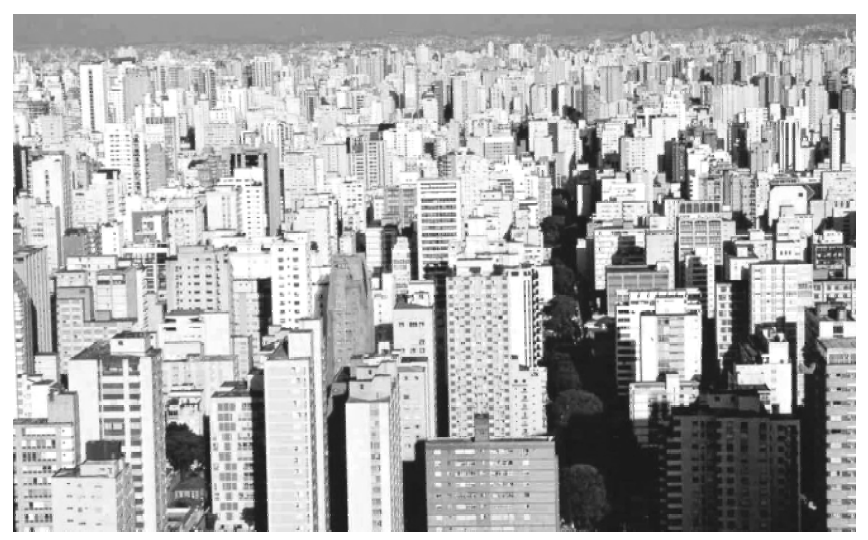

Foto 10 Exemplo de padrão urbano classe média e mista com verticalização, morfologia original de espigão em terrenos sedimentares Terciários, estágio pós-intervenção. Foto: Angela Garcia. 
RODRIGUES, C. (2005). Original and anthropogenic morphology to identify units of urban planning; the case of São Paulo. Revista do Departamento de Geografia, n. 17, p. 101-111.

Abstract: This study is an example of application of methodology to approach main interferences in terrestrial surface, proposed by RODRIGUES (1990, $1997,1999,2003)$. That methodology implies among others needs to consider the geomorphological systems in its different stages of disturbances such as pre-disturbance, active disturbance and post-disturbance. It also includes the view in witch man interferences are analyzed as geomorphological actions and should be considered as interferences in forms, materials and processes. It demonstrates how the same type of original landforms in São Paulo Metropolitan area can change into different derivative and anthropogenic landforms and starts with cartographic recognization of original morphologic units moving on to the consideration of the sequence of human interferences in forms and materials. The procedure is presented in two different and complementary scales: first, in big scales, such as 1:25000 and 1: 10000 considering a period of thirty years and further in small scales such as 1: 100000 and 1:250000 considering a period of one hundred years. The tests demonstrate how the different combinations of original and anthropogenic landforms can result in complex urban units and why those units should be taken into account so as to explain the derivative processes and to adopt urban planning procedures.

Key words: Antrhopogenic geomorphology; Anthropic morphology; Impact in physical environment; Urban planning; Environmental cartography; Urban geoindicators.

Recebido em 7 de setembro de 2005, aceito em 10 de dezembro de 2005.

\section{Referências}

AB'SABER, A.N. (1957) Geomorfologia do Sítio Urbano de São Paulo. São Paulo, Universidade de São Paulo. Tese de Doutorado.

COLTRINARI, L. (1996) Natural and anthropogenic interactions in the brazilian tropics in: Geoindicators. Assessing rapid environmental changes in earth systems. BERGER e IAMS. Bakema / Rotterdam Brookfield.

BATISTA, C.C. (2003) Conversa cartográfica: Processo de expansão urbana na metrópole paulistana e unidades geomorfológicas de média escala. Departamento de Geografia, FFLCH, USP. Trabalho de Graduação.

DOUGLAS, I. (1975) The impact of urbanization on fluvial geomorphology in the humid tropics. In: Symposium on Environmental Geomorphology in the Tropical Regions. Lubumbashi. Geo-Eco Trop.

GREGORY, K.J. (1992) A natureza da geografia Física. Rio de Janeiro, Bertrand Brasil.

HART, M.G. (1986) Geomorphology, pure and applied. London,
George Allen e Unwin.

DOUGLAS, I. (1983) The Urban Environment. Edward Arnold, Baltimore, Maryland.

GOUDIE, A. (1994) The Human Impact on the Natural Environment. The MIT Press, Cambridge, Massachusetts, 4th ed.

LIMA, C.R. (1990) Urbanização e intervenções no meio físico na borda da bacia sedimentar de São Paulo, uma abordagem geomorfológica. São Paulo, Universidade de São Paulo. Dissertação de Mestrado.

NIR, D. (1983) Man, a geomorphological agent: an introduction to anthropic geomorphology. Jerusalem, Ketem Pub. House.

RODRIGUES, C. (1997) Geomorfologia Aplicada: Avaliação de experiências e de instrumentos de planejamento físico-territorial e ambiental brasileiros. São Paulo, universidade de São Paulo. Tese de Doutorado.

RODRIGUES, C. (2004) A urbanização da Metrópole sob a perspectiva da geomorfologia. In CARLOS, A.F. e OLIVEIRA, A.U. Geografias de São Paulo. São Paulo, Contexto. V. 1, p. 89-114. 